TITLE:

\title{
Characteristics of a persistent current compensator for superconducting NMR magnets using linear type magnetic flux pump
}

\section{$\operatorname{AUTHOR}(\mathrm{S})$ :}

Chung, YD; Muta, I; Hoshino, T; Nakamura, T

\section{CITATION:}

Chung, YD ...[et al]. Characteristics of a persistent current compensator for superconducting NMR magnets using linear type magnetic flux pump. IEEE TRANSACTIONS ON APPLIED SUPERCONDUCTIVITY 2005, 15(2): 1338-1341

\section{ISSUE DATE:}

2005-06

URL:

http://hdl.handle.net/2433/39958

\section{RIGHT:}

(c)2005 IEEE. Personal use of this material is permitted. However, permission to reprint/republish this material for advertising or promotional purposes or for creating new collective works for resale or redistribution to servers or lists, or to reuse any copyrighted component of this work in other works must be obtained from the IEEE. 


\title{
Characteristics of a Persistent Current Compensator for Superconducting NMR Magnets Using Linear Type Magnetic Flux Pump
}

\author{
Yoon Do Chung, Itsuya Muta, Tsutomu Hoshino, and Taketsune Nakamura
}

\begin{abstract}
This paper describes the characteristics of a linear type magnetic flux pump for compensating current in a superconducting coil with 10 A operating current. The linear type flux pump has been fabricated to use for compensating persistent current decay of HTS applications such as NMR and MRI systems. Pumping current of the linear type magnetic flux pump mainly can be controlled by frequency of AC current. In the experiment, it has been demonstrated that the linear type magnetic flux pump can effectively charge and discharge the current in the load coil of $543 \mathrm{mH}$ for various frequencies with the DC bias of $10 \mathrm{~A}$ and the $\mathrm{AC}$ of $5 \mathrm{~A}_{r m s}$. Moreover, experimental results of temperature distribution of a slow response PCS have been compared with simulation.
\end{abstract}

Index Terms-Linear type magnetic flux pump, $\mathrm{Nb}$ foil, persistent current compensator.

\section{INTRODUCTION}

$\mathbf{M}$ OST recently, the application for the superconducting power supply is very promising in high- $T c$ superconducting (HTS) coil applications such as magnetic resonance image-CT (MRI-CT) and nuclear magnetic resonance spectrometer (NMR) used for life science fields [1]-[3]. Compared with low-Tc superconductors (LTS), since HTS coils have a low $n$-index value, HTS coils could not keep the persistent current constant [4]-[6]. Superconducting flux pumps are mainly classified into rotating type and rectifier type. In this paper, we originally proposed linear type magnetic flux pump which makes less vibration and electric noise than the early-developed flux pump and can control pumping current by frequency of AC current [7], [8]. Consequently, a static linear type magnetic flux pump would be thought to be most suitable to compensate the persistent current decay.

In this experiment we observed pumping rate of the load coil to measure small quantities of pumping current using a hall sensor. We determined the ramp-up rates of pumping current in the load coils with DC bias current of $10 \mathrm{~A}, 3$-phase $\mathrm{AC}$ current of $5 \mathrm{~A}_{r m s}$ and operating current of $10 \mathrm{~A}$. In addition to, experimental results of a temperature distribution of a slow

Manuscript received October 4, 2004. This work was supported by Grant-in-Aid for exploratory research (no. 14655107) of JSPS, and the 21st Century COE Program (no. 14213201) in Japan.

The authors are with the Electrical Engineering Department, Kyoto University, Kyoto, 615-8510, Japan (e-mail: yoondo@asl.kuee.kyoto-u.ac.jp; muta@kuee.kyoto-u.ac.jp; hosinio@kuee.kyoto-u.ac.jp; tk_naka@kuee.kyotou.ac.jp).

Digital Object Identifier 10.1109/TASC.2005.849589

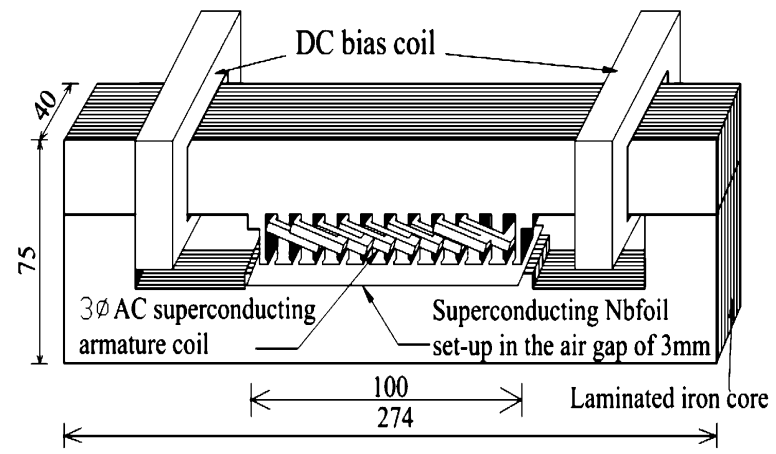

Fig. 1. Schematic diagram of the linear type magnetic flux pump.

response persistent current switch (PCS) have been compared with simulations.

\section{STRUCTURE AND OPERATIONAL PRINCIPLE}

\section{A. Structure}

The linear type flux pump is mainly composed of four components as follows:

1) Laminated core

2) DC bias coil

3) 3-phase $\mathrm{AC}$ armature coil

4) $\mathrm{Nb}$ foil.

Fig. 1 shows a schematic diagram of the linear type magnetic flux pump that is connected to a 6-coil toroidal load magnet for the test. The Nb-Ti conductor of $\phi 0.9 \mathrm{~mm}$ is used for the DC bias magnet coil and the load coil of the flux pump. The Nb-Ti twisted multifilament conductor of $\phi 0.6 \mathrm{~mm}$ is used for 3-phase $\mathrm{AC}$ armature coils. A sheet of superconducting $\mathrm{Nb}$ foil of $20 \mu \mathrm{m}$ thick, $60 \mathrm{~mm}$ wide and $120 \mathrm{~mm}$ long, is installed in the air gap of $3 \mathrm{~mm}$. The $\mathrm{Nb}$ foil is sandwiched with translucent aluminum nitride ceramic thin plate with high thermal conductivity. The connection between the load coil and the $\mathrm{Nb}$ foil is done by spot welding method. Table I provides parameters for DC coil, 6-coil toroidal load magnet and 3-phase AC coil.

\section{B. Operational Principle}

As is well known, a three-phase winding produces a traveling magnetic field in the air gap of Fig. 1 where a Nb foil is installed. Its magnitude is adjustable by the amplitude of the three-phase current, and its traveling speed depends on the frequency of applied power source. On the other hand, two DC bias coils in 
TABLE I

PARAMETERS OF COILS

\begin{tabular}{|c|c|}
\hline \multicolumn{2}{|c|}{ DC COIL } \\
\hline $\begin{array}{l}\text { Wire } \\
\text { Wire diameter }[\mathrm{mm}] \\
\text { Turns / coil } \\
\text { Length / coil }[\mathrm{m}] \\
\text { Inside dimension }\left[\mathrm{mm}^{2}\right] \\
\text { Outside dimension }\left[\mathrm{mm}^{2}\right]\end{array}$ & $\begin{array}{l}\mathrm{Nb}-\mathrm{Ti} / \mathrm{Cu} \quad(1 / 3.3) \\
0.9 \\
132 \\
23 \\
3 \times 4.6 \\
4.8 \times 6.2 \\
\end{array}$ \\
\hline \multicolumn{2}{|c|}{ LOAD COIL } \\
\hline $\begin{array}{l}\text { Wire } \\
\text { Wire diameter [mm] } \\
\text { Turns / coil } \\
\text { Length / coil [m] } \\
\text { Inside dimension [mm] } \\
\text { Outside dimension [mm] } \\
\text { Inductance [mH] }\end{array}$ & $\begin{array}{l}\mathrm{Nb}-\mathrm{Ti} / \mathrm{Cu} \quad(1 / 3.3) \\
0.9 \\
142 \\
72 \\
\phi 40 \\
\phi 80 \\
1.3 \\
\end{array}$ \\
\hline \multicolumn{2}{|c|}{ 3-PHASE AC COIL } \\
\hline $\begin{array}{l}\text { Wire } \\
\text { Ic@ } 4.2 \mathrm{~K}, 50 \mathrm{~Hz}\left[\mathrm{~A}_{\text {peak }}\right] \\
\text { Wire diameter [mm] } \\
\text { Turns / phase } \\
\text { Total length / phase [m] }\end{array}$ & $\begin{array}{l}\mathrm{Nb}-\mathrm{Ti} \\
42 \\
0.6 \\
40 \\
25 \\
\end{array}$ \\
\hline
\end{tabular}

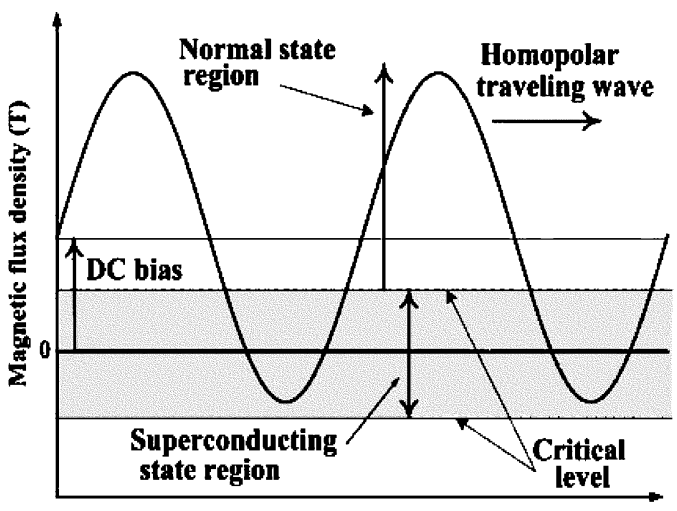

Linear slot length

Fig. 2. Homopolar traveling wave for DC bias and 3-phase AC excitations in the air gap.

Fig. 1 play a role in producing a homopolar magnetic field in such an air gap. Fig. 2 illustrates the ideal homopolar traveling magnetic field with 3-phase AC excitation, and DC bias. Under this condition, the $\mathrm{Nb}$ foil installed in the air gap is superconducting for part of a cycle, and extends the normal state when the critical field is exceeded.

While in the normal state, some magnetic flux can definitely penetrate the $\mathrm{Nb}$ foil, traveling toward the superconductive circuit, which consists of the load coil connected to the $\mathrm{Nb}$ foil through superconducting wires. Since such a completely superconductive circuit should generally keep linkage flux constant according to Lenz's law, some persistent current must flow to keep them constant, resulting in pumping-up the persistent current. As a result, the continuously traveling homopolar magnetic flux continues to increase the persistent current in the positive or negative direction.

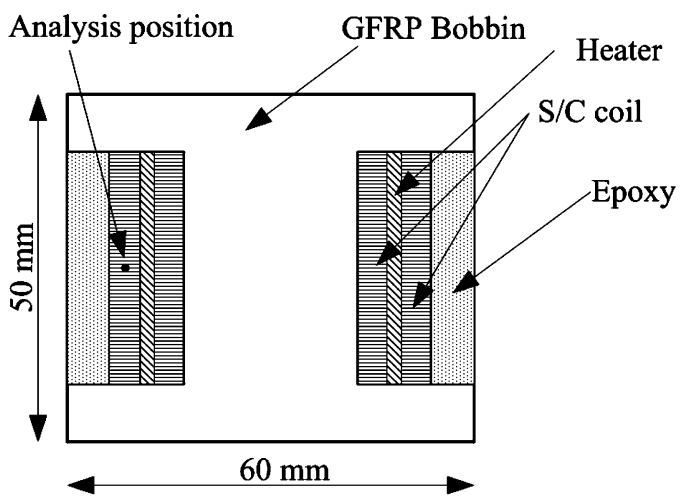

Fig. 3. Structure for slow response PCS and marked analysis position.

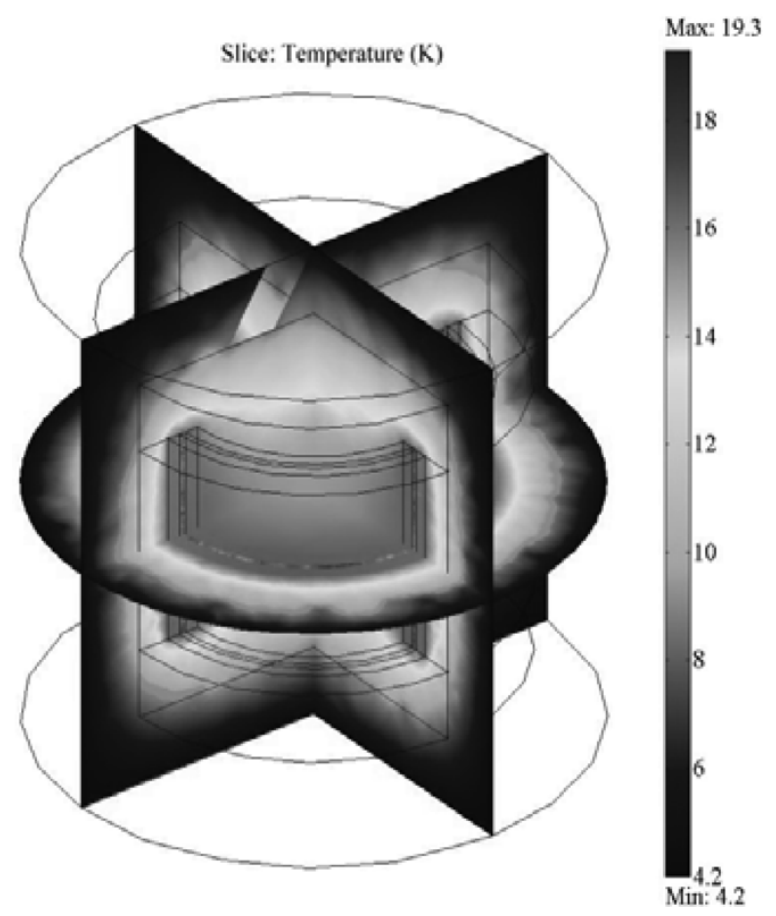

Fig. 4. Simulated result for the PCS by heater transfer analysis of heating current of $80 \mathrm{~mA}$ during 20 seconds.

\section{SLOW RESPONSE PCS}

\section{A. Structure}

We fabricated a slow response PCS system to keep operating current at $10 \mathrm{~A}$ and made computer simulations of the temperature distribution for slow-response PCS with 3-D thermal transfer analysis. The PCS consists of four parts as follows: GFRP bobbin, superconducting $\mathrm{Nb}-\mathrm{Ti}$ coil, $\mathrm{NiCr}$ wire of heater and Epoxy. The structure of the PCS with superconducting coil and marked analysis position are shown in Fig. 3. Fig. 4 shows 3-D thermal transfer analysis results for slow response PCS with heating current of $80 \mathrm{~mA}$ during 20 seconds heating. Fig. 5 shows the simulated result for temperature distribution at the superconducting coil marked position in Fig. 3. Under these conditions the maximum temperature of the superconducting coil reaches $17.8 \mathrm{~K}$. As the critical temperature of $\mathrm{Nb}-\mathrm{Ti}$ is around $9.2 \mathrm{~K}$, The coil effectively begins to keep switch off state over $9.2 \mathrm{~K}$. Table II provides parameters for the slow response PCS. 


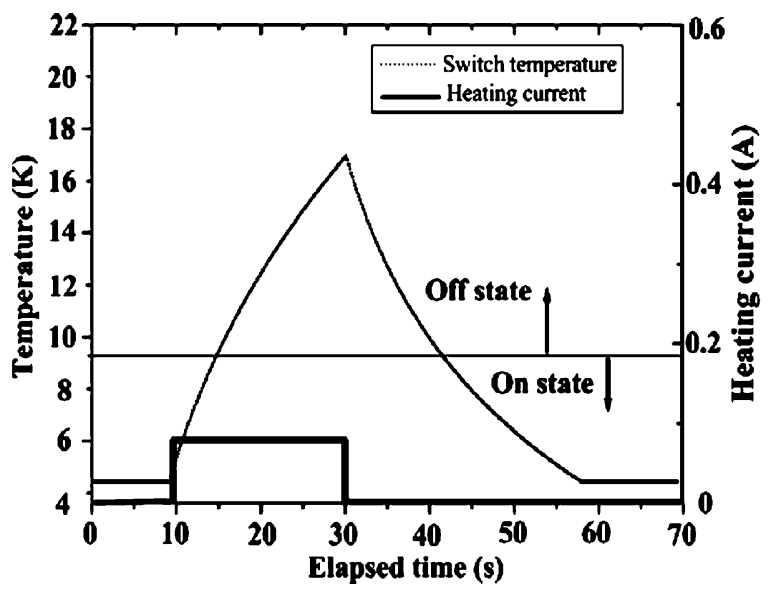

Fig. 5. Calculated temperature distribution at the center of S/C coil and outside layer with the heating current of $80 \mathrm{~mA}$.

TABLE II

SPECIFICATIONS OF SLOW RESPONSE PCS

\begin{tabular}{ll}
\hline \hline Wire & CuNi:Cu:NbTi = 2.88:0.35:1 \\
Wire diameter [mm] & 0.57 \\
Filament number & 9720 \\
Filament diameter $[\mu \mathrm{m}]$ & 2.5 \\
DC critical current $[\mathrm{A}] /[\mathrm{T}]$ & $260 / 1$ \\
Heater thickness [mm] & 0.05 \\
Wide of heater [mm] & 1 \\
Length of heater $(\mathrm{NiCr}$ wire) [m] & 2.5 \\
Heater Resistance $[\Omega] @ 4.2 \mathrm{~K}$ & 221 \\
Length of NbTi coil [m] & 18.2 \\
I.O of the bobbin [mm] & 40 \\
Thickness of epoxy [mm] & 6 \\
\hline \hline
\end{tabular}

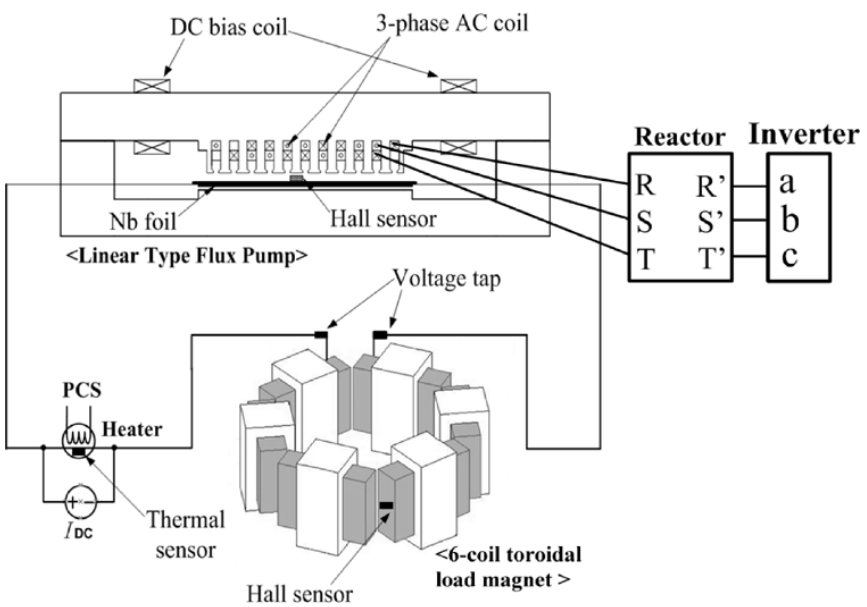

Fig. 6. Connection diagram for linear type magnetic flux pump system.

\section{EXPERIMENTAL SETUP}

The connection diagram of the flux pump system is shown in Fig. 6. In the flux pump system, two Hall sensors and one thermal sensor are used at the following positions: in the central air gap of the flux pump, a transverse type Hall sensor measures magnetic flux density generated by the DC bias and measures temperature distribution in the PCS. The reactor is installed between 3-phase AC coil and inverter, to produce AC excitations in the air gap between two toroidal cores, an axial type Hall sensor calibrates the pump-up current in the Nb-Ti load coil, on the superconducting coil, a thermal sensor measures temperature distribution in the PCS. The reactor is installed between

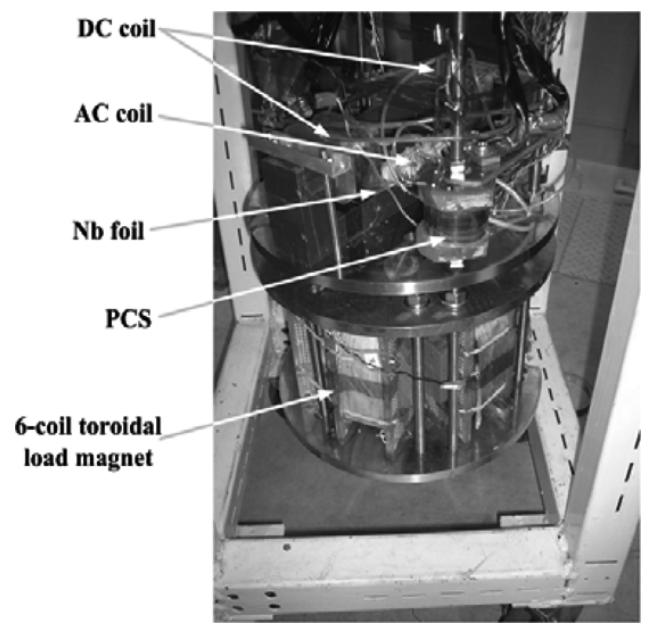

Fig. 7. Photograph of the linear type magnetic flux pump system.

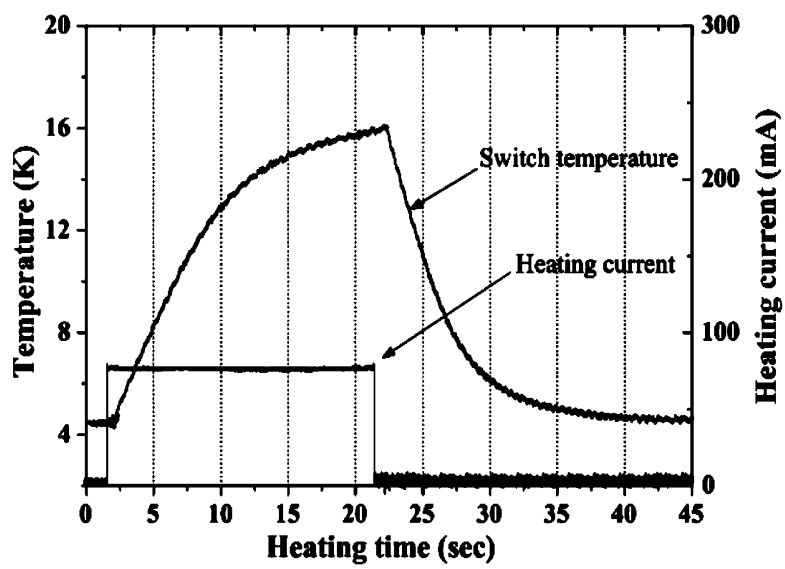

Fig. 8. Measured temperature distribution for PCS in the S/C coil with heating current $80 \mathrm{~mA}$ during 20 seconds.

3-phase AC coil and inverter to produce clear sinusoidal wave of 3-phase AC current from inverter. The resistance values of $\mathrm{R}-\mathrm{R}^{\prime}, \mathrm{S}-\mathrm{S}^{\prime}$ and $\mathrm{T}-\mathrm{T}^{\prime}$ in the reactor are 38.2, 37.9 and $38.5 \Omega$, respectively. Fig. 7 shows a photograph of whole assembly flux pump system.

All signals are automatically recorded and monitored through the data acquisition system at the same time.

\section{RESULTS AND DISCUSSIONS}

In this experiment, we measured the pumping current for the DC bias of $10 \mathrm{~A}$ and the 3-phase $\mathrm{AC}$ of $5 \mathrm{~A}_{r m s}$ of 10,15 and $20 \mathrm{~Hz}$ as well as the temperature distribution for slow response PCS. Fig. 8 shows the experimental results for temperature distribution of slow response PCS with heating current of $80 \mathrm{~mA}$ and heating time of 20 seconds. Under this condition, the maximum temperature of the superconducting coil reaches $16.1 \mathrm{~K}$. Fig. 9 shows the experimental results for magnetic flux density at center of the linear core with the DC bias of $10 \mathrm{~A}$ and the 3-phase AC of $5 \mathrm{~A}_{r m s}$ at 10,15 and $20 \mathrm{~Hz}$. It has been measured that the maximum and minimum magnetic flux densities are about $+0.10 \mathrm{~T}$ and $-0.02 \mathrm{~T}$, respectively. The measured pump-up and -down current with DC of $10 \mathrm{~A}$ and $\mathrm{AC}$ of $5 \mathrm{~A}$ at $10 \mathrm{~Hz}, 15 \mathrm{~Hz}$ and $20 \mathrm{~Hz}$ are shown in Figs. 10, 11 and 12 . The maximum pump-up currents at $10 \mathrm{~Hz}, 15 \mathrm{~Hz}$ and $20 \mathrm{~Hz}$ during 15 minutes reach $10.75,11.32$ and $11.78 \mathrm{~A}$, respectively. 


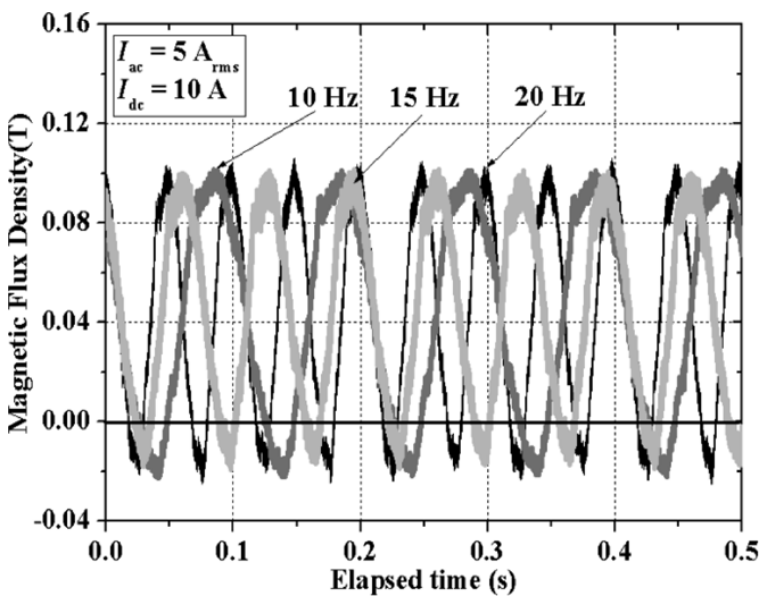

Fig. 9. Measured magnetic flux density at the center of the linear core with DC bias of $10 \mathrm{~A}$ and 3-phase $\mathrm{AC}$ of $5 \mathrm{~A}_{r m s}$.

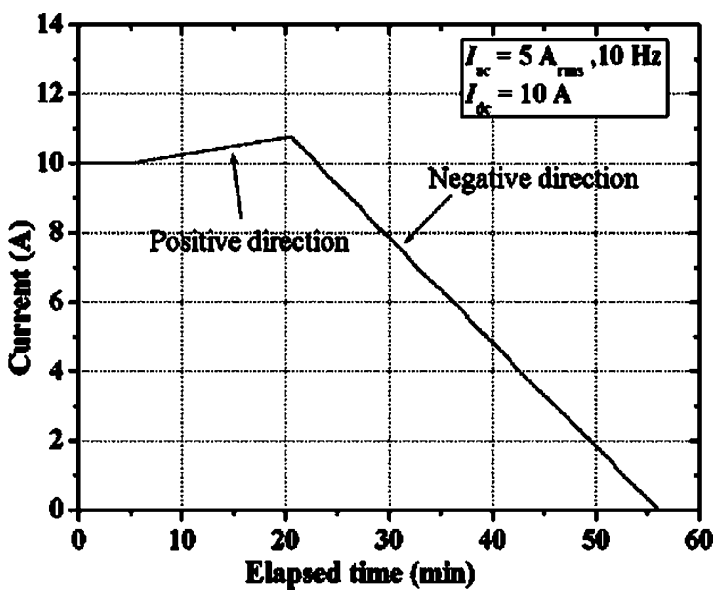

Fig. 10. Measured results for pump-up and -down current with DC of $10 \mathrm{~A}$ and $\mathrm{AC}$ of $5 \mathrm{~A}_{\mathrm{rms}}$ at $10 \mathrm{~Hz}$ and operating current of $10 \mathrm{~A}$.

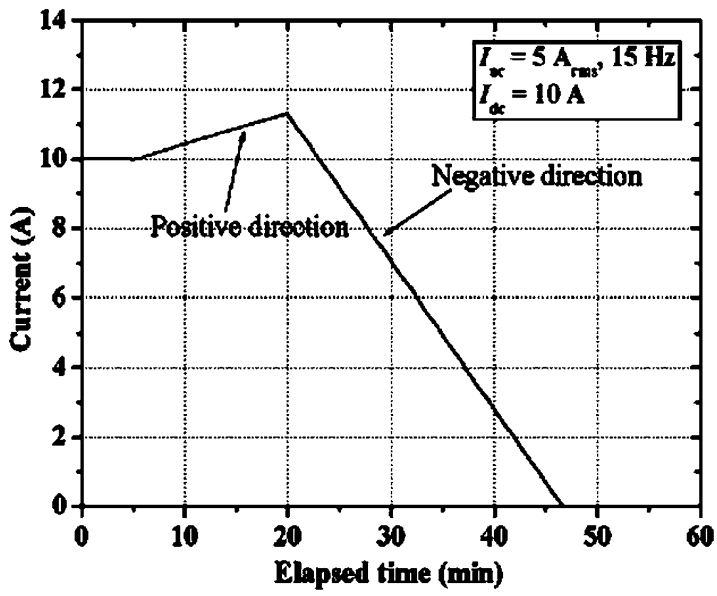

Fig. 11. Measured results for pump-up and -down current with DC of $10 \mathrm{~A}$ and $\mathrm{AC}$ of $5 \mathrm{~A}_{\mathrm{rms}}$ at $15 \mathrm{~Hz}$ and operating current of $10 \mathrm{~A}$.

Moreover, the pump-up current rates at 10,15 and $20 \mathrm{~Hz}$ are $0.83,1.47$ and $1.98 \mathrm{~mA} / \mathrm{s}$, respectively. On the other hand, the pump-down current rates at 10,15 and $20 \mathrm{~Hz}$ are $-0.51,-0.69$ and $-10.8 \mathrm{~mA} / \mathrm{s}$, respectively.

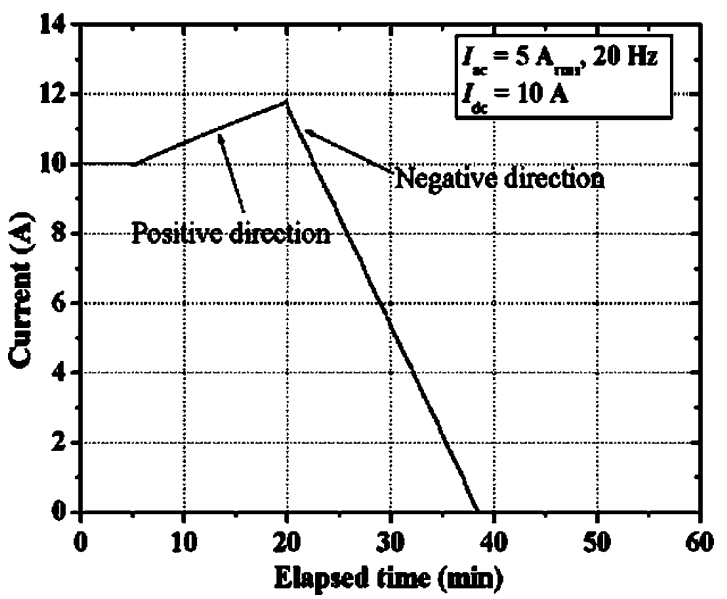

Fig. 12. Measured results for pump-up and -down current with DC of $10 \mathrm{~A}$ and $\mathrm{AC}$ of $5 \mathrm{~A}_{\mathrm{rms}}$ at $20 \mathrm{~Hz}$ and operating current of $10 \mathrm{~A}$.

From these experimental results, it should be proved that the linear type magnetic flux pump can effectively control the pump-up and -down current by the frequencies of $\mathrm{AC}$ current.

\section{CONCLUSION}

Pump-up and -down currents characteristics for the linear type magnetic flux pump have been practically investigated with the operating current of $10 \mathrm{~A}$. We observed that the flux pump can stably charge and discharge the current into the load magnet of $543 \mathrm{mH}$ by frequency of AC current. The switch on-off operations were effectively measured. Moreover, the measured results agreed with simulated ones. Therefore, based on such experimental results, it is expected that the linear type magnetic flux pump as a stable persistent current compensator can apply for HTS magnets in NMR and MRI systems.

Furthermore, at the next stage, we will investigate whether the flux pump can compensate persistent current decay of 6-coil toroidal magnet using automatic feedback control circuit system.

\section{REFERENCES}

[1] L. J. M. van de Klundert and H. H. J. ten Kate, "Fully superconducting rectifiers and flux pumps," Cryogenics, vol. 21, pp. 195-206, 1981.

[2] L. M. Barkov, N. S. Bashtovoy, V. S. Karpov, A. A. Ruban, V. P. Amakhtin, I. G. Snopkov, and I. V. Zhuravkov, "Superconducting rectifier flux pump for magnet system of the CMD-2 detector," IEEE Trans. Appl. Superconduct., vol. 3, pp. 4585-4590, Sep. 1999.

[3] W. D. Markiewick, "Current injection for field decay compensation in NMR spectrometer magnet," IEEE Trans. Appl. Superconduct., vol. 12, pp. 1886-1890, Dec. 2002.

[4] Y. Iwasa, "Microampere flux pump for superconducting NMR magnets part 1; basic concept and microtesla flux measurement," Cryogenics, vol. 41, pp. 385-391, 2001.

[5] H. G. Lee, J. Bascunan, and Y. Iwasa, "A high-temperature superconducting double-pancake insert for an NMR magnet," IEEE Trans. Appl. Superconduct., vol. 13, pp. 1546-1549, Jun. 2003.

[6] S. K. Jeong, "Experiment of flux pump for high temperature superconductor insert coils of NMR magnets," Journal of the Korea Institute of Applied Superconductivity and Cryogenics, vol. 3, no. 2, pp. 15-20, Nov. 2001.

[7] Y. Chung, I. Muta, T. Hoshino, T. Nakamura, and T. Ko, "Pumping-up current characteristics of linear type magnetic flux pump," Journal of the Korea Institute of Applied Superconductivity and Cryogenics, vol. 6, no. 2, pp. 29-34, May 2004.

[8] Y. D. Chung, I. Muta, T. Hoshino, T. Nakamura, and M. H. Sohn, "Design and performance of compensator for decremental persistent current in HTS magnets using linear type magnetic flux pump," Cryogenics, vol. 44, no. 11, pp. 839-844, Nov. 2004. 